\title{
Effect of Moisture Content On The Time-Dependent Mechanical Characteristics of Loess
}

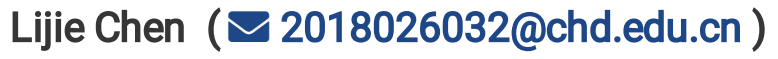

Chang'an University https://orcid.org/0000-0002-8724-7713

Jianbing Peng

Chang'an University https://orcid.org/0000-0003-4689-7717

\section{Fei Xie}

Chang'an University

\section{Yanqiu Leng}

Chang'an University

\section{Penghui Ma}

Chang'an University

Jingjing Nan

Xijing University

Ruixin Yan

Xi'an Technological University

\section{Research Article}

Keywords: Loess, Moisture content, Time-dependent strain, Shear strength, Long-term strength, microstructure change

Posted Date: September 9th, 2021

DOI: https://doi.org/10.21203/rs.3.rs-846846/v1

License: (1) This work is licensed under a Creative Commons Attribution 4.0 International License. Read Full License

Version of Record: A version of this preprint was published at Environmental Earth Sciences on March 30th, 2022. See the published version at https://doi.org/10.1007/s12665-022-10326-8. 


\section{Abstract}

It is of great significance to study the time-dependent mechanical properties of loess, as loess landslides are closely related to them. The purpose of this study is to investigate the effect of moisture content on instantaneous and time-dependent deformation, strength and failure behaviors of undisturbed loess specimens from Nangou in Yan'an City, Shanxi Province, China, via triaxial shearing tests and multi-loading triaxial creep tests under moisture contents of $5 \%, 10 \%, 17 \%$ and $22 \%$. The results show that the timedependent deformation of loess increase with the moisture content, while the time-dependent deformation rate decreases slowly. The soil deformation is divided into four stages based on the peak strain rate. Furthermore, the instantaneous and long-term strength of loess decrease with increasing moisture content, and the instantaneous strength decreases more than the long-term strength. The failure mode of undisturbed loess changes from shear failure to homogeneous failure with increasing moisture content; when the failure mode is shear failure, the thickness of the shear band that forms at the specimen surface over time is smaller than the corresponding thickness that forms instantaneously. Finally, the macroscopic morphology and microstructure of loess specimens were considered together to analyze the effect of moisture content on the instantaneous and long-term mechanical behavior of loess and to discuss the process of loess deformation to failure.

\section{Introduction}

With the help of the Belt and Road Initiative, the economy of the loess region in China has further developed, but with the increasing intensity of human activities, the problems of geological disasters are increasing rapidly, among which loess landslides pose a great threat to the safety of people's lives and urban construction in loess regions ( Cui et al. 2018; Macfarlane 2009; Padilla et al. 2014; Smith 2015; Wen and Jiang 2017; Wu et al. 1978). Through long-term monitoring and analysis of landslides, many scholars have found that the time effect of soil is an important factor in inducing landslides (Dijkstra et al. 1994; Li et al. 2013; Wang et al. 1993). (Hu et al. 1965; Xin et al. 2016) carried out kinematic analysis of large landslides on the Loess Plateau in Baoji, China, simulated the deformation mechanism of sliding-zone soil, and found that the creep characteristic of sliding-zone soil induced the generation of landslides. (Yates et al. 2018) conducted the instability mechanism of loess in Canterbury, New Zealand, and found that the creep characteristics of saturated loess were the main cause of slope instability. (Wang et al. 2020) pointed out that the creep behavior of loess was an important factor that induced the Baqiao landslide. Loess is the building material and host material of foundation engineering construction in the Loess Plateau region of China. It is very important to study the effect of time on the mechanical properties of loess, which can provide an important theoretical basis for the advanced identification of loess landslides.

At present, scholars have mainly studied the influence of different factors on the time dependence of soil mechanical properties and established a model to simulate the change process of soil over time. The methods used include laboratory tests (creep tests, stress relaxation tests), physical model tests, and in situ field tests (Tang et al. 2020; Zhu and Yu 2015). For example, (Wang and Luo 2010) performed creep tests on loess, analyzed the creep characteristics of loess under one-dimensional stress conditions, and proposed an empirical formula to simulate the relationship between the shear modulus, consolidation stress and 
time. (Lei et al. 2015) analyzed the stability of loess slopes through a series of drainage triaxial creep tests on loess samples. (Zhou et al. 2016) conducted a triaxial creep test of frozen soil under different confining pressures and temperatures and established a rate-dependent constitutive model of frozen loess samples based on multi-internal variable superplasticity theory. (Li et al. 2018) carried out a high-pressure consolidation creep test and analyzed the influence of the initial moisture content, compactness, consolidation pressure and other factors on the creep characteristics of remolded loess. (Chang et al. 2020) studied the creep characteristics of Malan loess considering matric suction, connected the nonlinear damper element in series with the Burgers model, combined with the functional relationship between the viscoelastic modulus and matric suction, and established the stress-absorption-strain-time model (an improved Burgers model). (Duan and Peng 2015; Tang et al. 2015) studied the influence of moisture content on the time dependence of $\mathrm{Q}_{2}$ loess mechanical properties through triaxial creep testing. (Wang et al. 2020) studied and analyzed the creep characteristics of loess from the Baqiao landslide, China, with different moisture contents, proposed a method to determine its long-term strength, and modified the Burgers model to describe the accelerated creep state of the soil.

The key to preventing engineering problems and geological disasters is to understand the influence of the time dependence of the soil mechanical properties and to analyze the generation and development of soil mechanical properties (strength and deformation) with time. (Tan 1988) proposed a microstructural model of Chinese loess, which could explain the sensitivity of the collapsibility and mechanical properties of this macroporous loess to moisture content. (Chen et al. 2005) carried out a series of creep tests on undisturbed soil and remolded soil and found that the deformation process of soil was actually a process of consolidation and creep and that the proportion of these two kinds of deformation in terms of the total deformation at any time depended on a variety of factors (stress level, drainage conditions, etc.). (Li and Jiang 2010) analyzed the microstructure changes of remolded loess in the uniaxial creep process from CT images and found that each layer of loess had a very complex fracture distribution; the cracks distributed irregularly along the radial direction, and the transverse deformation was not obvious. (Yang et al. 2014) carried out microstructure tests on dredged soft soil at multiple time points in the creep process, extracted the variation in the particle and pore parameters, and studied the change in the microstructure in the creep process. (Luo et al. 2016) conducted a one-dimensional secondary consolidation test and consolidated undrained triaxial creep test on dredged soft clay, systematically analyzed the creep characteristics and mechanism of this soft clay, and established a Merchant model with fractional derivatives. (Xie et al. 2018; Zhou et al. 2020) studied the changes in the particle and pore structure of loess in different creep stages through SEM and quantitatively studied the evolution characteristics of microscopic pores in the creep process.

This paper is based on triaxial shear tests and triaxial creep tests on undisturbed loess from the Yan'an area, Shaanxi Province, China. The aim of this work is to investigate the shear mechanical behavior of undisturbed loess under the time effect during the shearing process, analyze the influence of moisture content on the strength and deformation of undisturbed loess, study the variation in the time-dependent deformation rate of undisturbed loess, categorize the deformation states of soil under long-term static 
loading, and explore the shear deformation process of undisturbed loess. This work is of great significance to the prevention of loess landslides.

\section{Samples And Methods}

\subsection{Soil sample properties}

The soil samples used in the present experimental tests were obtained from the foot of a slope at a side in Nangou in Yan'an City, Shaanxi Province, China (Fig. 1). The soil was classified as Malan loess; it was yellowish brown, had a homogeneous fabric, and included many vertical joints. The natural mass moisture content ( $\omega$, the moisture content referred to below is the mass moisture content) of the undisturbed loess was $10 \%$, and the natural density $(\rho)$ was $1.55 \mathrm{~g} / \mathrm{cm}^{3}$. Other physical properties are listed in Table 1 .

Table 1

Physical parameters of the undisturbed loess in the natural state

\begin{tabular}{|c|c|c|c|c|c|c|c|c|c|}
\hline \multirow[t]{2}{*}{$G$} & \multirow[t]{2}{*}{$W_{\mathrm{P}}$} & \multirow[t]{2}{*}{$W_{L}$} & \multirow[t]{2}{*}{$I_{p}$} & \multirow[t]{2}{*}{$W_{\text {sat }}$} & \multirow[t]{2}{*}{$\rho_{d}$} & \multirow[t]{2}{*}{$\rho_{\max }$} & \multicolumn{3}{|c|}{ Grain content (\%) } \\
\hline & & & & & & & <. $005 \mathrm{~mm}$ & $0.005 \sim 0.075 \mathrm{~mm}$ & $0.075 \sim 2 \mathrm{~mm}$ \\
\hline 2.71 & 16.9 & 29.1 & 12.2 & 32.69 & 1.409 & 1.72 & 8.34 & 74.19 & 17.47 \\
\hline
\end{tabular}

\subsection{Instruments}

All the triaxial creep tests and triaxial shear tests were carried out on undisturbed loess using a soil rheological triaxial testing machine (CSS-TSS10DL) at Chang'an University of China. This instrument is composed of a host system, an axial measurement and control system, a confining pressure measurement and control system, a pore water flow measurement system, and a computer system. It can be used to measure the short-term shear strength and rheological properties of soil. Under the control of a constant load $(0-10 \mathrm{kN})$ or constant deformation $(0-20 \mathrm{~mm})$, the changes in the axial stress or axial strain of the specimen can be tested, as well as the pore water pressure $(0-2 \mathrm{MPa})$ and pore water flow $\left(0-20 \mathrm{~cm}^{3}\right)$ inside the specimen.

\subsection{Test methods}

The test specimens were prepared from the undisturbed loess specimens to meet the required dimensions of a diameter of $39.1 \mathrm{~mm}$ and a height of $80 \mathrm{~mm}$. The air drying method and water film transfer method were used to prepare loess specimens with a target moisture content, namely, $5 \%, 10 \%, 17 \%$, and $22 \%$. To ensure a uniform moisture content distribution in the loess specimens, the specimens were kept in a sealed container for approximately $48 \mathrm{~h}$. In this test, considering the position of the loess at the sampling site, the consolidated undrained method was adopted. The confining pressure $\left(\sigma_{3}\right)$ was selected to be $200 \mathrm{kPa}$. The 
ambient temperature of the experiment was controlled within $(20 \pm 1)^{\circ} \mathrm{C}$. The specific test steps are as follows:

(1) The shear strength $\left(\sigma_{f}=\left(\sigma_{7}-\sigma_{3}\right)_{f}\right)$ of undisturbed loess specimens with different moisture contents was determined through a consolidated undrained triaxial shear test under a confining pressure of $200 \mathrm{kPa}$. The shear rate of the test was kept constant at $0.06 \mathrm{~mm} \cdot \mathrm{min}^{-1}$, and the test was stopped when the axial strain reached $20 \%$. During the test process, the axial stress and axial strain were recorded every 5 seconds. At the end of the test, the confining pressure and axial stress were reduced to zero. The shear strength of the specimen was obtained by the resulting stress-strain curve.

(2) A consolidated undrained triaxial creep test was performed on specimens with different moisture contents in this study. The specimens were consolidated at a confining pressure of $200 \mathrm{kPa}$. The static load value of the creep test was determined by the shear strength, which was obtained in the previous step. The loading method of the creep test adopted multistage loading, divided into 6 loading levels $\left(0.1 \sigma_{f} 0.2 \sigma_{f}\right.$ $0.3 \sigma_{f} 0.4 \sigma_{f} 0.5 \sigma_{f}$ and $0.6 \sigma_{f}$ ). The specific scheme is shown in Table 2. During the process of the creep test, the static load was maintained until the strain was stable and the subsequent level of load could be applied. This step was repeated until the specimen failed. In this study, the criterion for creep stability is that the deformation of the specimens was less than $0.01 \mathrm{~mm}$ within $12 \mathrm{~h}$, according to Standard of the Ministry of Water Resources of China (SL264-2001) and the suggestion by (Wang et al. 2020), the loading time of each static level in this test was $24 \mathrm{~h}$. In this study, failure occurred when the strain reached $15 \%$.

Table 2

Loading scheme of triaxial creep test for the specimens

\begin{tabular}{|c|c|c|c|c|c|c|c|c|}
\hline \multirow[t]{2}{*}{$\begin{array}{l}\text { Loading } \\
\text { levels }\end{array}$} & \multirow[t]{2}{*}{$\begin{array}{l}\text { Confining } \\
\text { pressure }\end{array}$} & \multirow[t]{2}{*}{$\begin{array}{l}\text { Loading } \\
\text { method }\end{array}$} & \multirow[t]{2}{*}{$\begin{array}{l}\text { Shearing } \\
\text { mode }\end{array}$} & \multicolumn{4}{|c|}{$\begin{array}{l}\text { Long-term static load } \\
\text { (kPa) }\end{array}$} & \multirow[t]{2}{*}{$\begin{array}{l}\text { Creep } \\
\text { duration }\end{array}$} \\
\hline & & & & $5 \%$ & $10 \%$ & $17 \%$ & $22 \%$ & \\
\hline First level & \multirow[t]{6}{*}{$200 \mathrm{kPa}$} & \multirow{6}{*}{$\begin{array}{l}\text { multi-stage } \\
\text { loading }\end{array}$} & \multirow[t]{6}{*}{$\mathrm{CU}$} & 84 & 58 & 47 & 32 & \multirow[t]{6}{*}{$24 \mathrm{~h}$} \\
\hline $\begin{array}{l}\text { Second } \\
\text { level }\end{array}$ & & & & 168 & 116 & 94 & 64 & \\
\hline Third level & & & & 252 & 174 & 141 & 96 & \\
\hline $\begin{array}{l}\text { Fourth } \\
\text { level }\end{array}$ & & & & 336 & 232 & 188 & 128 & \\
\hline Fifth level & & & & 420 & 290 & 235 & 160 & \\
\hline sixth level & & & & 504 & 348 & 282 & 192 & \\
\hline
\end{tabular}

\section{Test Results}

To distinguish the stress and strain obtained from the triaxial shear test and triaxial creep test, the stress (strain) obtained from the triaxial shear test and triaxial creep test is called the instantaneous stress (instantaneous strain) and time-dependent stress (time-dependent strain), respectively, in this paper. 
Therefore, this paper analyzes the instantaneous and time-dependent mechanical properties of undisturbed loess under different moisture contents according to the test results.

\subsection{Instantaneous stress-strain relationship of loess}

To investigate the effect of moisture content on the instantaneous deformation characteristics of loess, the results of the consolidated undrained triaxial shear tests under a confining pressure of $200 \mathrm{kPa}$ are considered. The instantaneous stress and strain curves of undisturbed loess under moisture contents of $5 \%$, $10 \%, 17 \%$, and $22 \%$ are shown in Fig. 2.

As shown in Fig. 2, the instantaneous deformation characteristics of undisturbed loess with different moisture contents are different during the shear process. Under a low moisture content, the instantaneous stress increases rapidly to the peak point at a relatively small strain (approximately $2 \%$ ) and thereafter gradually decreases, i.e., showing strain softening behavior. With increasing moisture content (from 5-10\%, $17 \%$ and $22 \%$ ), the instantaneous stress increases rapidly with strain, and then the instantaneous stress remains stable or slowly increases with instantaneous strain. Thus, the stress-strain curve properties change from strain softening to strain hardening. Additionally, the higher the moisture content is, the later the inflection point on the stress and strain curve and the lower the degree of strain hardening. Although the instantaneous shear deformation characteristics of loess specimens with different moisture contents are different, the instantaneous stress-strain curves can be divided into two stages: (1) when the instantaneous strain is small, the instantaneous stress of loess specimens has a linear relationship with the instantaneous strain (corresponding to the elastic deformation stage); (2) when the peak point/inflection point of instantaneous stress is reached, the range of increase in the instantaneous stress decreases considerably with increasing strain (at this point, the loess specimens enter the stage of elastoplastic deformation).

The failure modes of undisturbed loess with different moisture contents are different. Under a low moisture content (hard plastic soils with a strong structure), although the specimen does not bulge significantly in the radial direction, a continuous shear band that is clearly visible on the side of the specimen forms, and its direction is oblique to the direction of major principal stress, i.e., shear failure (Fig. 2a and b). With increasing moisture content, the soil structure decreases, and the failure mode of the specimens changes from shear failure to homogeneous failure, which is characterized by uniform compaction of the whole specimen without obvious bulging deformation or shear fracturing (Fig. 2c and d).

\subsection{Time-dependent strain characteristics of loess}

Based on the triaxial creep test, when the confining pressure is $200 \mathrm{kPa}$, the correlations between the total time-dependent strain and time of undisturbed loess with different moisture contents at long-term static load are shown in Fig. 3. To more accurately study the time-dependent strain characteristics of loess, the Chen method (Tan and Kang, 1991) is adopted to obtain the time-dependent strain and time curves of loess specimens under different moisture contents and different static load levels, as shown in Fig. 4.

The total strain of loess specimen mainly includes the instantaneous strain during the static loading stage and the time-dependent strain during the static load stabilizing stage (Вялов 1987). As shown in the Fig. 3, 
with increasing static load, both the instantaneous deformation and the creep deformation of the loess specimens increase. Under certain conditions, the deformation generated by large loads is far greater than that generated by the accumulation of multiple small loads. Test results under a moisture content of $5 \%$ and different static loads are selected as examples. The total deformation under the action of the first five levels of load is $5.67 \mathrm{~mm}$, and the deformation under the action of the sixth level of load is $12.8 \mathrm{~mm}$, which indicates the destruction of the soil specimen.

Figure 4 shows that the time-dependent strain of the undisturbed loess has nonlinear characteristics. The curve of the change in time-dependent strain with time under long-term static loading can be divided into three typical deformation stages, namely, the decelerated deformation stage, the steady-state deformation stage and the accelerated deformation stage (Вялов 1987). According to Fig. 4, under the first five levels of static loading, the specimens experience the decelerated deformation stage only. As the static load continues to increase to level six, a specimen might continue to experience the deceleration stage (e.g., the moisture contents of the specimens in Fig. $4 \mathrm{~b}$ and Fig. $4 \mathrm{~d}$ are $10 \%$ and $22 \%$, respectively), the acceleration stage and be destroyed immediately (e.g., the moisture content of the specimen in Fig. $4 \mathrm{a}$ is $5 \%$ ), or the acceleration stage and finally break down after a short period of viscous flow (e.g., the moisture content of the specimen in Fig. $4 \mathrm{c}$ is $17 \%$ ). Therefore, whether a specimen will undergo all three stages is related to the selection of the long-term static load.

Figure 5 shows the different loading stages strain curves in the three-dimensional space of moisture $(\omega)-$ long-term static load $\left(\sigma_{D}\right)-\operatorname{strain}\left(\varepsilon_{t}\right)$. The deformation characteristics of soil are different with increasing moisture content, which is mainly reflected in the following aspects: (1) The critical load value of specimens decreases with the increase of moisture content. (2)The instantaneous deformation and time-dependent deformation increases with moisture content. (3) With the increase of long-term static load, the instantaneous deformation and time-dependent deformation increase, and the lower the moisture content, the greater the degree of their change. In addition, with moisture content increase, it takes longer for specimens to undergo the stable stage under long-term static loading (Fig. 4), and the failure mode of undisturbed loess changes from shear failure (Fig. 3a) to homogeneous failure (Fig. 3b and c and d)

\subsection{Time-dependent strain rate characteristics of loess}

The strain rate can clearly and accurately reflect the variation in soil deformation per unit time. To better examine the effect of various factors (the moisture content, time and long-term static load) on loess deformation, based on the data shown in Fig. 4, the relationship between the time-dependent strain rate of the undisturbed loess with different moisture contents and time is shown in Fig. 6.

The influence of time on the strain rate of loess can be explained by Fig. 6: the strain rate of loess specimens decreases with time under a low long-term static load. In the initial stage of load stabilization, the strain rate decreases rapidly with time; as time increases, it remains almost constant and then decreases to zero. However, when the long-term static load is high, the strain rate increases with time in the initial stage, and as the strain rate increases to the peak point, it enters the decay stage, which is roughly the same as the attenuation trend under the condition of a low long-term static load. The phenomenon of the increase in strain rate can be interpreted as the fact that the internal resistance of the loess specimens 
cannot resist the applied force in a short time under a high static load, so the strain rate increases, and then the internal structure of the soil is adjusted to a stable state to make it resistant to external forces, causing the strain rate of the soil to decrease.

Figure 6 also clearly shows that the moisture content has a significant effect on the strain rate and the degree of variation under long-term static loading. The higher the moisture content is, the slower the soil strain rate decay, the smaller the peak strain rate, and the longer the time to reach the stable stage. In addition, the higher the moisture content is, the earlier the increase in the strain rate, and the longer the time to reach the peak point of the strain rate.

The abovementioned findings suggest that the peak point of the strain rate is the critical point at which the soil has the ability to resist external forces. According to the data in Fig. 6, the correlation between the peak strain rate and long-term static load at different moisture contents is shown in Fig. 7.

Figure 7 shows that the peak strain rate does not always increase with the long-term static load. To more accurately study the variation in peak rate, different moisture contents are comprehensively analyzed. According to the comprehensive analysis, there may be three inflection points of the peak strain rate of loess specimens with different long-term static loads, which can be regarded as the critical points of the transformation of the soil deformation state ((Вялов 1987) distinguished three critical stress levels, namely, the elastic limit stress, flow limit stress and complete failure stress according to the deformation state characteristics of soil).

The quartic polynomial is used to fit the experimental data in Fig. 7, as shown in Fig. 7, and their relationships are shown in Eq. (1):

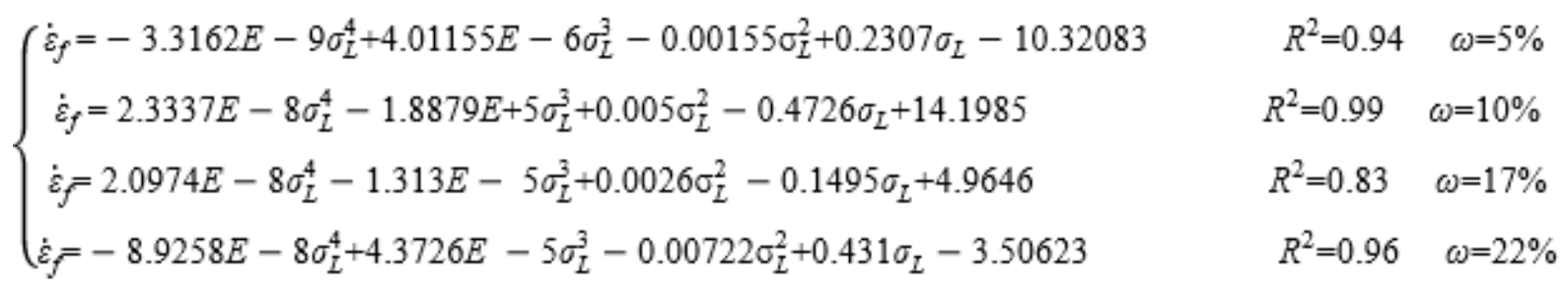

Clearly, the fitting data of the peak strain rate and long-term static load show good agreement with the experimental data. Therefore, we obtain the critical stress of undisturbed loess with different moisture contents from the data in Fig. 7, and the specific values are shown in Table 3.

Table 3

Long-term strength of undisturbed with different moisture content

\begin{tabular}{|lllll|}
\hline Critical stress $(\mathrm{kPa})$ & \multicolumn{4}{l|}{ Moisture content (\%) } \\
\cline { 2 - 5 } & $\mathbf{5}$ & $\mathbf{1 0}$ & $\mathbf{1 7}$ & $\mathbf{2 2}$ \\
\hline Elastic limit stress & 133.11 & 72.87 & 39.63 & 47.43 \\
\hline Flow limit stress & 248.61 & 224.93 & 182.45 & 139.1 \\
\hline Complete failure stress & 515.54 & 325.15 & 246.55 & 180.79 \\
\hline
\end{tabular}


The state of stress, strain and energy have been considered to judge the failure and yielding of soil (Sun, 1999). In this paper, we study the variation in the strain rate of loess specimens with time, which is used as a parameter to judge the deformation state of loess. The critical point from the flow limit stress to the complete failure stress is defined as the long-term strength.

\subsection{Time-dependent strength characteristics of loess}

To explore the strength characteristics of loess under the time-dependent strain state, the correlation between stress and strain at different moisture contents and different times is shown in Fig. 7. Additionally, the time points of $0 \mathrm{~h}, 0.3 \mathrm{~h}, 0.6 \mathrm{~h}, 1 \mathrm{~h}, 2 \mathrm{~h}, 4 \mathrm{~h}, 8 \mathrm{~h}, 12 \mathrm{~h}, 18 \mathrm{~h}$, and $24 \mathrm{~h}$ were chosen for analysis.

Figure 8 shows that the stress-strain curves at different times and different moisture contents have nonlinear characteristics. When the static load is small, the stress of the loess specimens is proportional to the strain. With increasing static load, the stress-strain curves gradually change from linear to nonlinear and then show distinct inflection points. The inflection point can be explained by the structural characteristics of the undisturbed loess. This finding is in agreement with a previous study conducted by (Yang 2011), who concluded that the structure of soil is the main cause of the inflection point and that the stress at the inflection point can be considered the structural yield strength of the soil. Moreover, the structure of the soil decreases with increasing moisture content, which explains why the inflection points of the curves of the loess specimens with high moisture contents remain almost unchanged.

The strain-stress curves of loess specimens at different times and different moisture contents have basically the same variation trend. The main phenomena are as follows: first, the strain of the loess specimens increases with stress, and then the stress-strain curves bend in the horizontal direction (strain axis). Furthermore, the stress-strain curves at different times exhibit obvious discrete phenomena, but their degrees of discreteness are different. This paper takes the stress-strain curves of loess specimens with a moisture content of $22 \%$ at different times as an example. There is an obvious discrete phenomenon between the curves from $t=0 \mathrm{~h}$ to at $t=4 \mathrm{~h}$, but the degree of discreteness gradually decreases. This can be explained as the time-dependent strain of soil gradually transforming from the decelerated stage to the steady-state stage. Under a long-term static load, the curve differences from $t=4 \mathrm{~h}$ to $t=24 \mathrm{~h}$ were minor. This is interpreted to be due to the strain of soil entering the steady-state stage and the small influence of the time effect on soil deformation.

The moisture content has a significant effect on the degree of dispersion of the time-dependent stressstrain curves at different times. The higher the moisture content is, the greater the degree of curve bending to the transverse axis (strain axis), the smaller the discreteness in the decelerated stage, and the longer the time required to enter the steady-state stage. For example, for the loess specimens with a moisture content of $10 \%$, the specimen deformation enters the steady-state stage when the long-term load is loaded for $8 \mathrm{~h}$; however, the specimen with a moisture content of $22 \%$ does not enter the steady-state stage when the longterm static load is loaded for $12 \mathrm{~h}$.

\section{Discussion}




\subsection{Effect of moisture content on the shear deformation of loess}

Natural sedimentary soils form various structures during long geological processes (Graham and Li 1985; Jiang et al. 2014). Due to the resulting soil structure, the forms of the instantaneous stress-strain curve are different under different conditions (i.e., strain hardening behavior, strain softening behavior, and strain steady behavior) (Chen et al. 2004; Kruse et al. 2007; Shen and Chen 2002; Wen and Yan 2014; Xing et al. 2016). (Shen and Chen 2002) suggested that the stress-strain curve of structural geomaterials in the instantaneous shear process is hardened or softened depending on whether the loss of cementation force can be compensated by friction. For the undisturbed soil with $5 \%$ moisture content, the friction generated by $200 \mathrm{kPa}$ of confining pressure is not enough to compensate for the loss of soil cementation stress under the corresponding moisture content, so the soil deformation characteristics show a strain softening behavior. The friction generated by soil specimens with water contents of $10 \%, 17 \%$ and $22 \%$ under $200 \mathrm{kPa}$ of confining pressure can completely compensate for the loss of the soil cementation stress during the shear process, and the soil deformation characteristics show a strain hardening behavior.

In addition, the difference in the time-dependent strain of undisturbed loess is obvious under different moisture contents. The strain and time curves of specimens with moisture contents of $10 \%$ and $22 \%$ were compared, as shown in Fig. 9. This figure indicates that compared with the loess specimens with low moisture contents, the instantaneous deformation of the loess specimens with high moisture contents was larger, the deformation attenuation rate was slower, and the start of the stable stage was delayed. This finding is consistent with previous research reported by (Tang et al. 2020; Wang et al. 2020). This phenomenon can be explained by the influence of water on the soil microstructure shown in Fig. 10. Firstly, the increase in moisture destroys the original equilibrium relationship of the soil particles, dissolves the carbonate cements in the soil, weakens the cementation between soil particles, and increases the amount of flocs and clay materials at the contacts and on the surfaces of the particles. Secondly, the increase in moisture destroys the connection between soil particles, reduces the soil particle group sizes, and makes the skeleton particles of the specimens more irregular and fragmented. Then, the pore sizes decrease, but the connectivity of pores increases (Hu et al. 2000; Luo et al. 2018). Moreover, with increasing moisture content, the bound water film between soil particles becomes thicker, the lubrication between soil particles increases, and the friction between soil particles decreases (Horn and Deere 1962; Lian et al. 2020; Xie et al. 2018; Xu et al. 2008), which makes the deformation of soil more likely. In addition, due to the poor drainage conditions, the water cannot be fully discharged during the shearing process, and it will take a long time for the soil particles to reach a stable equilibrium.

\subsection{Moisture content effect on the shear strength of loess}

Based on the test data shown in Table 3, the relationship between moisture content, shear strength and long-term strength under $200 \mathrm{kPa}$ is presented in Fig. 11.

As shown in Fig. 11, the shear strength of loess and moisture content have a negative logarithmic relationship. In other words, both shear strength and long-term strength decrease with the increase of water 
content, and the degree of strength reduction decreases. Similar results were also observed from conventional triaxial tests in a number of studies (Cui et al., 2019; Lian et al., 2019). The shear strength of loess is mainly composed of the cohesion (c) and the friction strength (otan $\varphi$ ). (Li, 2018; Nan et al., 2021) found that the influence of water on the shear strength of soil is mainly the influence on the cohesion of soil rather than the internal friction angle. The reason is that the internal friction angle of loess is mainly affected by the internal factors such as soil density, particle grading, particle shape and mineral composition(Zhao, 1994). The cohesion of loess consists of original cohesion (namely electrostatic force and van der Waals force) solidified cohesion (i.e. crystallization and cementation between particles) and apparent cohesion (i.e. physicochemical effect of water film) (Li, 2014; Li et al., 2013; Milligan and Houlsby, 1984). The original cohesion is produced by the long-term pressure of geological time and is relatively stable, while the solidified cohesion and apparent cohesion are significantly affected by external factors such as time and water content, which are mainly reflected in the following aspects: Firstly, when the water content in the soil increases, the matric suction and the pore gas pressure decreases, the molecular attraction and tension from the surface of the shrink films on the water-air interface decrease, thus leading to the decrease of the apparent cohesion of the loess samples(Gu et al., 2019). Secondly, with the increase of water content, the hydration film between clay cemented particles and non-water-resistant cemented particles becomes thicker, the distance between soil particles increases, and the cementation strength (solidified cohesion) decreases(Li et al., 2019). In addition, water-soluble salts (e.g. fe-oxides, calcium carbonate and gypsum) exist in the pores of soil in a dissolved state, which strengthens the condensation of colloidal substances. When the water content increases, the decrease of water-soluble salts concentration resulting in the chemical reactions such as ion exchange on the cement surface, which will lead to clay expansion and dispersion, and reduce the cementation strength(Gao, 1979).

Figure 11 shows that the attenuation of the long-term strength $(50.23 \%$, from $325 \mathrm{kPa}$ to $139.66 \mathrm{kPa})$ is less than that of the instantaneous strength $(61.98 \%$, from $505 \mathrm{kPa}$ to $192 \mathrm{kPa})$. This is mainly caused by the loading of time. Figure 12 shows that compared with instantaneous loading, long-term loading can make the soil particle arrangement denser and more orderly, mainly in terms of the face contacts; as the compaction effect of the pores becomes more significant, the particles become more uniform. Thus, as the internal structure of the soil can fully enter the substable state under time, which reduces the weakening of the soil strength caused by moisture content, the attenuation degree of the long-term strength of specimens with moisture content is less than that of the instantaneous shear strength (Taylor and Merchant, 1940; Zhao et al., 2020).

Under a consistent moisture content, the instantaneous strength of a loess specimen is greater than its time-dependent strength. This can be explained by the destruction of the soil structure over time. From the microscopic point of view (Fig. 12), compared with that under instantaneous shear, the soil structure of the specimen under long-term shear is broken to a greater extent, there are more clay particles on the surface, the number of macropores decreases more, and the number of micropores and small pores increases more.

\subsection{Analysis of the shearing process of loess}


The strength of soil depends on its cohesion and friction (Chen et al. 2004; Schmertmann 1991). At the beginning of shearing (the elastoplastic deformation stage), the strength of loess is mainly provided by cohesion (the cementation force between soil particles). As shearing continues, the internal structure of loess is damaged, and slip between particles occurs. With increasing strain, loess particles are compressed, compacted and rearranged, and part of the primary pore structure is filled with loess particles to form a new secondary structure (Fig. 12b), which makes the loess structure reach a relatively stable state (elastoplastic deformation stage), the strength of soil is mainly provided by the friction between particles. According to the above analysis, the instantaneous shear process of loess can be regarded as the process of interparticle bond damage (e.g., particle slippage, particle structure collapse, and particle damage), particle recombination (e.g., compression, extrusion, and rearrangement) and finally the formation of a relatively stable structure (e.g., from an overhead structure system to an interlocked-cementation structure system) (Nan et al. 2021; Taylor 1948; Wang 1997; Xu et al. 2019)

However, the variations in strength caused by interparticle bond damage and particle recombination are related to time under certain factors (e.g., the viscosity of a water film around a solid particle in soil or the connection of soil particles) (Chen et al. 2001; Вялов 1987), and the deformation of soil in the process of internal stress adjustment is time-dependent deformation. Figure $4 \mathrm{~h}$ is taken as an example to analyze the generation and development of time-dependent strain in undisturbed loess. The deformation of loess increases rapidly at the moment of loading, and the internal structure of the loess is damaged, This process is the same as that under instantaneous shear. When the load is stable and continuously loaded, the loess structure may still be damaged, but the soil particles are fully adjusted to form a relatively stable structure in the loess so that the resistance (sum of cohesion and friction) generated by the loess and the damage caused by the static load reach a relatively balanced state, and then the deformation of the loess tends to be stable (first five loads). However, if the load is too large, even if the loess particles are constantly adjusted, the resistance generated by the loess cannot resist the static load and cannot reach the relative balance state, so the deformation of the loess continues to increase until the soil reaches a relatively stable state. When the deformation reaches the critical value, it is declared that the loess specimen is destroyed (sixth load). In conclusion, it is considered that the alternation process of soil particle structure adjustment and damage after load stability is the process of time-dependent strain generation and development. This is essentially the same as the conclusion obtained by (He 2008; Yang 2011).

In summary, regardless of instantaneous shear or long-term shear, the shear process of soil is a process in which the internal stress of soil constantly adjusts to resist the external force. Compared with instantaneous shear, long-term shear can allow the full interaction among soil particles over time (Fig. 12c: directional arrangement of particles and more compact pores). However, the soil structure can also be damaged over time (Fig. 12c: smaller particles and particles breakage). Especially when the external force load is near the critical load, soil damage may occur under the condition of time. The higher the moisture content is, the greater the difference between the instantaneous shear and the long-term shear, i.e., the time dependence of the soil. Therefore, it is of great significance to study the time dependence and mechanism of loess mechanical properties to prevent disasters over time. 


\section{Conclusions}

The time-dependence mechanical properties of undisturbed loess is strongly influenced by the soil moisture content. To investigate this effect, triaxial shear tests and multiloading triaxial creep tests were carried out on undisturbed loess samples with different moisture contents. This paper presented the test results to clarify the influence of moisture content on the deformation and strength of undisturbed loess and shear process of loess. According to the test results and the abovementioned discussion, the following conclusions were drawn:

The failure mode of undisturbed loess under a low moisture content is shear failure. With increasing moisture content, the thickness of the shear band formed in a specimen decreases and even disappears, and the failure mode changes from shear failure to homogeneous failure. Under the same moisture content, the shear band of a specimen under long-term shear is less obvious than that under instantaneous shear.

The deformation of loess includes instantaneous deformation and time-dependent deformation, which are positively correlated with the moisture content and static load. The strain rate and its decay rate are negatively correlated with the moisture content. This is mainly because the increase in moisture destroys the internal microstructure of the soil, which reduces the cementation force and the friction between soil particles. In addition, there may be three inflection points in the relationship between the peak deformation rate and the static load, which can represent the critical points between different stages of time-dependent deformation. Based on these points, the long-term strength of the soil can be determined.

At the same moisture content, the stress-strain curves at different moments have obvious discreteness and nonlinearity, which decrease with increasing time. Then, the stress of undisturbed loess decreases with increasing moisture content. With increasing moisture content from 5-22\%, the instantaneous strength and long-term strength decreased by $61.98 \%$ and $50.23 \%$, respectively. The long-term strength decreases less than the instantaneous strength because time weakens the effect of water on the soil strength, which can be reflected by the microstructural variations in loess.

The macroscopic shear behavior of undisturbed loess is essentially caused by a change in its microstructure. The instantaneous shear process of loess can be regarded as the process of interparticle bond damage (e.g., particle slippage, particle structure collapse, and particle damage) and particle recombination (e.g., compression, extrusion, and rearrangement). The long-term shear process is an alternating process of continuous adjustment and damage of the soil particle structure when the long-term static load is stable.

The findings are of great significance for understanding the effect of water on the time-dependency mechanical properties of undisturbed loess. This study provides a theoretical basis for engineering construction and geological disaster prevention in loess areas. In addition, this study on the influences of water and time on the mechanical properties of loess from the mesoscopic viewpoint lays a foundation for future systematic studies of the mechanism of loess time-dependent deformation from the microscale perspective. 


\section{References}

1. Вялов CС (1987) Principle of mechanical rheology of soil. Beijing: Science Press.

2. Chang ZL, Gao HX, Huang FM, et al. (2020) Study on the creep behaviours and the improved Burgers model of a loess landslide considering matric suction. Nat Hazards 103(1): 1479-1497. https://doi.org/10.1007/s11069-020-04046-0

3. Chen TL, Zhou C, Shen, ZJ (2004) Compression and shear test of structured clay. Chin J Geotech Eng 26(1): 31-35 (in Chinese). https://doi.org/10.3321/j.issn:1000-4548.2004.01.005

4. Chen, XP, Zhu HH, Zhang FZ, et al. (2005) Experimental Study on Time-dependent Deformation of Soft Soil. Chin J Rock Mech Eng 24(12): 2142-2148 (in Chinese). https://doi.org/10.3321/j.issn:10006915.2005.12.023

5. Cui JY, Liu Y, Xie BL (2019) Mechanical Properties and Microcosmic Analysis of Undisturbed Loess in Xining Area with Different Moisture Content. IOP Conference Series: Earth Env Sci, 304: 32-36. https://doi.org/10.1088/1755-1315/304/3/032036

6. Cui SH, Pei XJ, Wu HY, et al. (2018) Centrifuge model test of an irrigation-induced loess landslide in the Heifangtai loess platform, Northwest China. J Mt Sci 15(1): 130-143. https://doi.org/10.1007/s11629017-4490-0

7. Dijkstra, TA, Rogers CDF, Smalley IJ, et al. (1994) The loess of north-central China: geotechnical properties and their relation to slope stability. Eng Geol 36(3-4): 153-171. https://doi.org/10.1016/01489062(94)90337-9

8. Duan Z, Peng JB (2015) Experimental Study of Triaxial Creep Characteristics of Q(2) Loess in Yan'an. I IWMECS 2015 33: 27-31. https://doi.org/10.2991/iwmecs-15.2015.6

9. Gao GR (1979) Study of the microstructures and the collapse mechanism in loess soil from Lanzhou. Journal of Lanzhou University, 6:123-134 (in Chinese).

10. Gu TF, Wang JD, Wang CX, et al. (2019) Experimental study of the shear strength of soil from the Heifangtai Platform of the Loess Plateau of China. J Soil Sediment, 19(10): 3463-3475. https://doi.org/10.1007/s11368-019-02303-9

11. Graham J, Li ECC (1985) Comparison of natural and remolded plastic clay. J Geotech Geoenviron Eng 111(7): 865-881. https://doi.org/10.1061/(asce)0733-9410(1985)111:7(865)

12. He Q (2008) Study on the Mechanical and Rheolgical Properties of Yan'an Q2 Loess. Dissertation, Chang'an University, Xian, China (in Chinese). https://doi.org/10.7666/d.y1528830

13. Horn HM, Deere DU (1962) Frictional characteristics of minerals. Géotechnique 12(4): 319-335. https://doi.org/10.1016/0022-4898(64)90086-2

14. Hu HT, Xiang SJ, Wang Z (1965) The characteristic constitution and structure of landslides in Western guanzhong region and analysis of their stability. Acta Geol Sin Eng 45(4): 435-465 (in Chinese). https://doi.org/CNKI:SUN:DZXE.0.1965-04-006

15. Hu ZQ, Shen ZJ, Xie DY (2000) Micro-structure and inundation of unsaturated loess. Hydro-Science and Engineering 02: 68-71 (in Chinese). https://doi.org/10.3969/j.issn.1009-640X.2000.02.013 
16. Jiang MJ, Zhang FG, Hu HJ, et al. (2014) Structural characterization of natural loess and remolded loess under triaxial tests. Eng Geo 181: 249-260. https://doi.org/10.1016/j.enggeo.2014.07.021

17. Kruse GA, Dijkstra TA, Schokking F (2007) Effects of soil structure on soil behaviour: Illustrated with loess, glacially loaded clay and simulated flaser bedding examples. Eng Geo 91(1): 34-45. https://doi.org/10.1016/j.enggeo.2006.12.011

18. Lei H, Yang CJ, Liu ZQ (2015) Loess triaxial creep test and revised Singh-Mitchell model. Water Resources and Power 33(10): 112-115 (in chinese). https://doi.org/CNKI:SUN:SDNY.0.2015-10-028

19. Li GX (2014) Advanced Soil Mechanics, Beijing: Tsinghua University Press.

20. Li GX, Zhang BY, Yu YZ (2013) Soil Mechanics Second Edition, Beijing: Tsinghua University Press.

21. Li JH. Fang HG, Wu SD (2018) Test on Creep Characteristics of Remolded Loess Under High Stress. J Henan Univ Sci Tech: Nat Sci Ed 39(3): 56-60 (in chinese). https://doi.org/10.15926/j.cnki.issn16726871.2018.03.011

22. Li TL, Wang P, Xi Y (2013) The mechanisms for initiation and motion of Chinese loess landslides. Progress of Geo-Disaster Mitigation Technology in Asia pp 105-122. https://doi.org/10.1007/978-3642-29107-4_5

23. Li XA, Li LC, Song YX, et al. (2019) Characterization of the mechanisms underlying loess collapsibility for land-creation project in Shaanxi Province, China-a study from a micro perspective. Eng Geo 249:7788. https://doi.org/10.1016/j.enggeo.2018.12.024

24. Li XJ, Jiang LH (2010) Micro-structure Change of Remolded Loess in Uniaxial Creep Test with Computerized Tomography. Civil Engineering in China - Current Practice and Research Report pp 642646.

25. Li YR (2018). A review of shear and tensile strengths of the Malan Loess in China. Eng Geo 236: 4-10. https://doi.org/10.1016/j.enggeo.2017.02.023

26. Lian BQ, Peng JB, Wang XG, et al. (2020) Moisture content effect on the ring shear characteristics of slip zone loess at high shearing rates. Bull Eng Geol Environ 79(2): 999-1008. https://doi.org/10.1007/s10064-019-01597-w

27. Lian BQ, Peng JB, Zhan HB, et al. (2019) Mechanical response of root-reinforced loess with various water contents. Soil Tillage Res 193: 85-94. https://doi.org/10.1016/j.still.2019.05.025

28. Luo H, Wu FQ, Chang JY, et al. (2018) Microstructural constraints on geotechnical properties of Malan Loess: a case study from Zhaojiaan landslide in Shaanxi province, China. Eng Geo 236: 60-69. https://doi.org/10.1016/j.enggeo.2017.11.002

29. Luo QZ, Chen XP, Wang S, et al. (2016) An experimental study of time-dependent deformation behaviour of soft soil and its empirical model. Rock Soil Mech 37(1): 66-75 (in chinese). https://doi.org/10.16285/j.rsm.2016.01.008

30. Macfarlane DF (2009) Observations and predictions of the behaviour of large, slow-moving landslides in schist, Clyde Dam reservoir, New Zealand. Eng Geo 109(1-2): 5-15.

https://doi.org/10.1016/j.enggeo.2009.02.005

31. Milligan GWE, Houlsby GT(1984) Basic soil mechanics. Butterworth Heinemann. 
32. Nan JJ, Peng JB, Zhu FJ, et al. (2021) Shear behavior and microstructural variation in loess from the Yan'an area, China. Eng Geo 280:105964. https://doi.org/10.1016/j.enggeo.2020.105964

33. Padilla C, Onda Y, lida T, et al. (2014) Characterization of the groundwater response to rainfall on a hillslope with fractured bedrock by creep deformation and its implication for the generation of deepseated landslides on Mt. Wanitsuka, Kyushu Island. Geomorphology 204(1): 444-458. https://doi.org/10.1016/j.geomorph.2013.08.024

34. Schmertmann JH. (1991) The Mechanical Aging of Soils. J Geotech Eng 117(9): 1288-1330. https://doi.org/10.1061/(asce)0733-9410(1991)117:9(1288)

35. Shen ZJ, Chen, TL (2002). Breakage Mechanics for Geological Materials Basic Concepts,Goal and Task. The 7th Academic Conference of Chinese Society of Rock Mechanics and Engineering 9: 9-12 (in chinese).

36. Smith JV (2015) Self-stabilization of toppling and hillside creep in layered rocks. Eng Geo 196(28): 139-149. https://doi.org/10.1016/j.enggeo.2015.07.008

37. Tan TK (1988) Fundamental properties of loess from Northwestern China. Eng Geo 25(2-4). https://doi.org/10.1016/0013-7952(88)90022-1

38. Tan TK, Kang,WF (1991) On the Locked in Stress, Creep and Dilatation of Rocks, and the Constitutive Equations. Chin J Rock Mech Eng 4:299-312 (in chinese). https://doi.org/10.1007/BF02945291

39. Tang H, Duan Z, Wang DP, et al. (2020) Experimental investigation of creep behavior of loess under different moisture contents. Bull Eng Geo Environ 79(1): 411-422. https://doi.org/10.1007/s10064-01901545-8

40. Tang H, Wang D, Duan Z, et al. (2015) Variable parameters creep damage model of loess based on fractional calculus. Journal of Central South University (Science and Technology) 46(11): 4248-4255. https://doi.org/10.11817/j.issn.1672-7207.2015.11.036

41. Taylor DW (1948) Fundamentals of soil mechanics. New York: John Wiley and Sons, Inc. London Chapman and Hall, Ltd.

42. Taylor DW, Merchant W (1940) A theory of clay consolidation accounting for secondary compression. Stud Appl Math 19: 167-185. https://doi.org/10.1002/sapm1940191167

43. Wang JD, Wang JT, Huang HG (1993) A study on creeping or sliding liquefaction of saturated soil. Geoscience 1: 102-108 (in chinese). https://doi.org/CNKI:SUN:XDDZ.0.1993-01-011

44. Wang SN (1997) Experimental study on mechanism of soil damage and its application. Guangdong Water Resources and Hydropower 6: 36-40. https://doi.org/CNKI:SUN:GDSD.0.1997-06-011

45. Wang SH, Luo YS (2010) Study on Shear Creep Characteristics of Structured Loess. Recent Developments of Geotechnical Engineering pp 636-643.

46. Wang XG, Wang JD, Zhan HB, et al. (2020) Moisture content effect on the creep behavior of loess for the catastrophic Baqiao landslide. Catena 187: 104371. https://doi.org/10.1016/j.catena.2019.104371

47. Wei YN (2019) Research on Three-dimensional Microstructure Evolution During Wetting and Collapsible Mechanism of Loess. Dissertation, Chang'an University, Xian, China (in Chinese). 
48. Wen BP, Jiang XZ (2017) Effect of gravel content on creep behavior of clayey soil at residual state: implication for its role in slow-moving landslides. Landslides 14(2): 559-576. https://doi.org/10.1007/s10346-016-0709-3

49. Wen BP, Yan YJ (2014) Influence of structure on shear characteristics of the unsaturated loess in Lanzhou, China. Eng Geo 168: 46-58. https://doi.org/10.1016/j.enggeo.2013.10.023

50. Wu TH, El Refai ANAA, Asu JRJ (1978) Creep deformation of clays. Int J Rock Mech Min 104(1): 61-76. https://doi.org/10.1016/0148-9062(78)91276-7

51. Xie X, Qi SW, Zhao FS, et al. (2018) Creep behavior and the microstructural evolution of loess-like soil from Xi'an area, China. Eng Geo 236: 43-59. https://doi.org/10.1016/j.enggeo.2017.11.003

52. Xie WL, Li P, Zhang MS, et al. (2018) Collapse behavior and microstructural evolution of loess soils from the Loess Plateau of China. J Mt Sci 15(8): 1642-1657. https://doi.org/10.1007/s11629-0185006-2

53. Xin P, Liang CY, Wu SR, et al. (2016) Kinematic characteristics and dynamic mechanisms of large-scale landslides in a loess plateau: a case study for the north bank of the Baoji stream segment of the Wei River, China. Bull Eng Geo Environ 75(2): 659-671. https://doi.org/10.1007/s10064-015-0824-8

54. Xing XL, Li TL, Fu YK (2016) Determination of the related strength parameters of unsaturated loess with conventional triaxial test. Environ Earth Sci 75(1):82. https://doi.org/10.1007/s12665-015-4797-5

55. Xu J, Wang ZQ, Ren JW, et al. (2008) Comparative Test Study on Deterioration Mechanism of Undisturbed and Remolded Loess during the Freeze-thaw Process. Chinese Journal of Underground Space and Engineering 3: 643-649 (in chinese). https://doi.org/CNKI:SUN:BASE.0.2018-03-011

56. Xu XT, Li QL, Lai Y, et al. (2019) Effect of moisture content on mechanical and damage behavior of frozen loess under triaxial condition along with different confining pressures. Cold Reg Sci Technol 157: 110-118. https://doi.org/10.1016/j.coldregions.2018.10.004

57. Yang AW (2011) Study on rheologic characteristics and its constitutive model of structured soft dredger fill. Dissertation, Tianjin University, Tianjin, China (in chinese). https://doi.org/10.7666/d.y2082290

58. Yang AW, Kong LW, Zhang XW (2014) Analysis of evolution of particles and pores in creep process of dredger fill soft soil. Rock Soil Mech 35(6): 1634-1640 (in chinese). https://doi.org/10.16285/j.rsm.2014.06.039

59. Yates K, Fenton CH, Bell DH (2018) A review of the geotechnical characteristics of loess and loessderived soils from Canterbury, South Island, New Zealand. Eng Geo 236: 11-21. https://doi.org/10.1016/j.enggeo.2017.08.001

60. Zhao D, Gao QF, Hattab M, et al. (2020) Microstructural evolution of remolded clay related to creep. Transportation Geotechnics 24: 100367. https://doi.org/10.1016/j.trgeo.2020.100367

61. Zhao ZX (1994) The influence of fissure on shear strength of soil. Subgrade Engineering 5:11-16(in chinese). https://doi.org/CNKI:SUN:LJGC.0.1994-05-002

62. Zhou JJ, Zhao FS, Yuan XQ, et al. (2020) Creep process and the microstructural evolution of slidingzone soil. Hydrogeology \& Engineering Geology 47(3): 115-121(in chinese).

https://doi.org/10.16030/j.cnki.issn.1000-3665.2019010011 
63. Zhou ZW, Ma W, Zhang SJ, et al. (2016) Multiaxial creep of frozen loess. Mech Mater 95: 172-191. https://doi.org/10.1016/j.mechmat.2015.11.020

64. Zhu YB, Yu HM (2015) Unsaturated creep behaviors of weak intercalated soils in soft rock of Badong formation. J Mt Sci 12(6): 1460-1470. https://doi.org/10.1007/s11629-014-3298-4

\section{Figures}

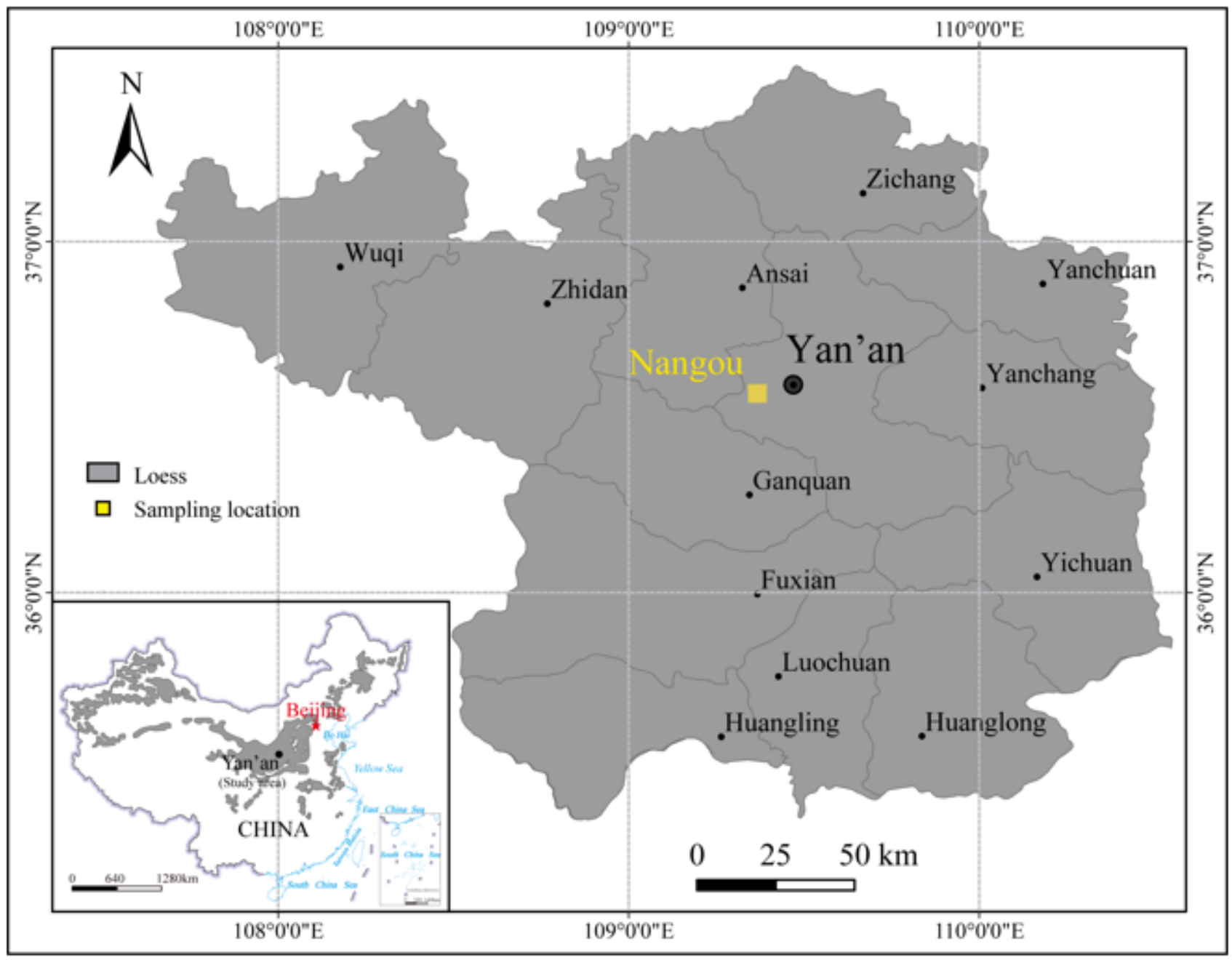

Figure 1

Distribution of loess in China and locations of the sampling site in Yan 'an city 

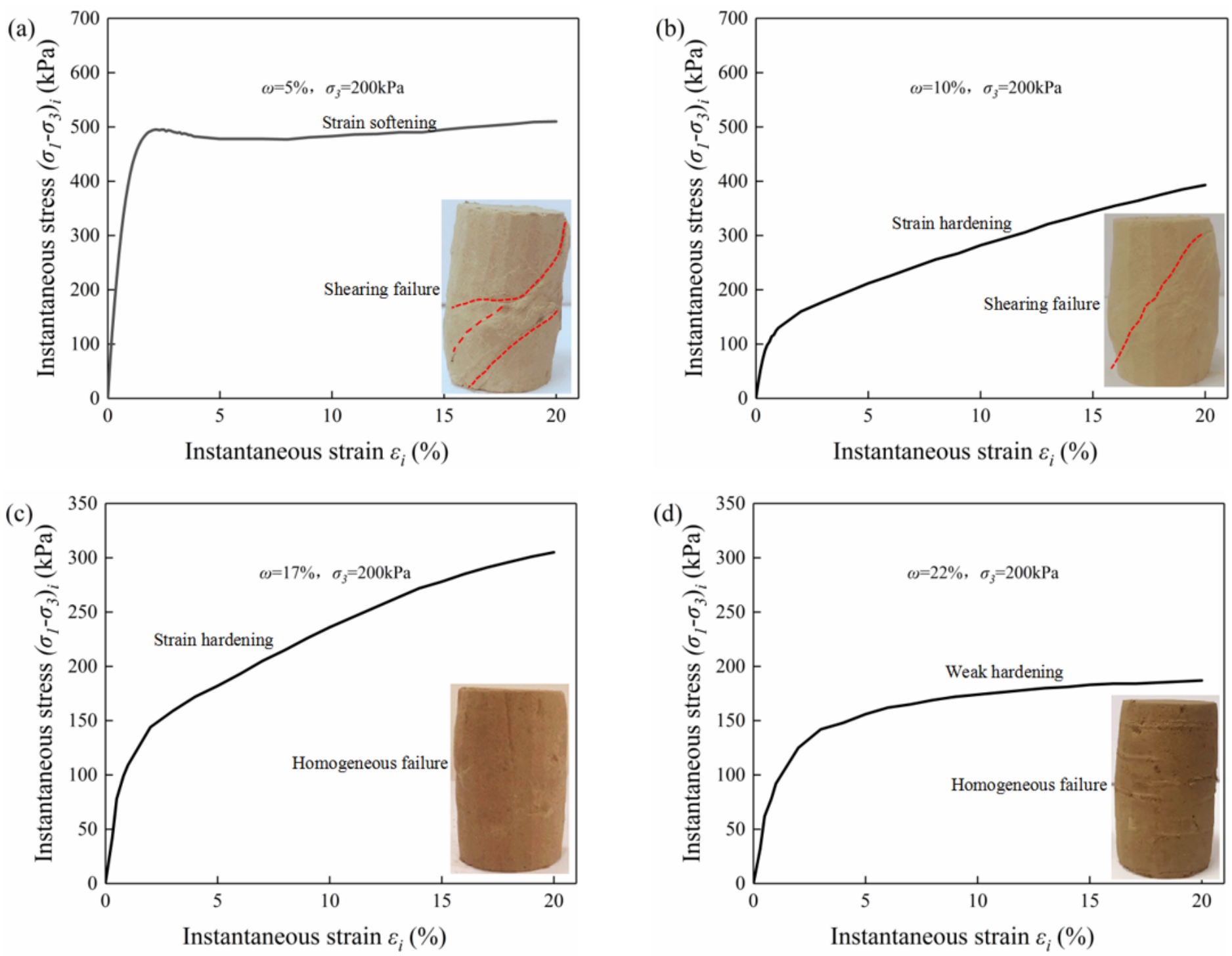

Figure 2

Curves of instantaneous stress versus instantaneous strain and failure modes of undisturbed loess under different moisture contents: (a) $\omega=5 \%$; (b) $\omega=10 \%$ (c) $\omega=17 \%$; (d) $\omega=22 \%$. $\omega$, moisture content; $\sigma 3$, confining pressure. 
(a)

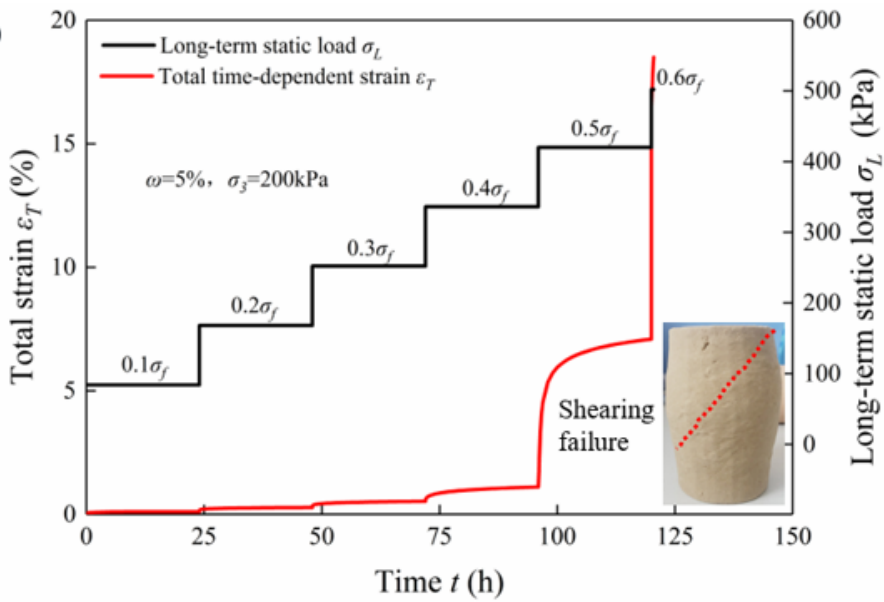

(c)

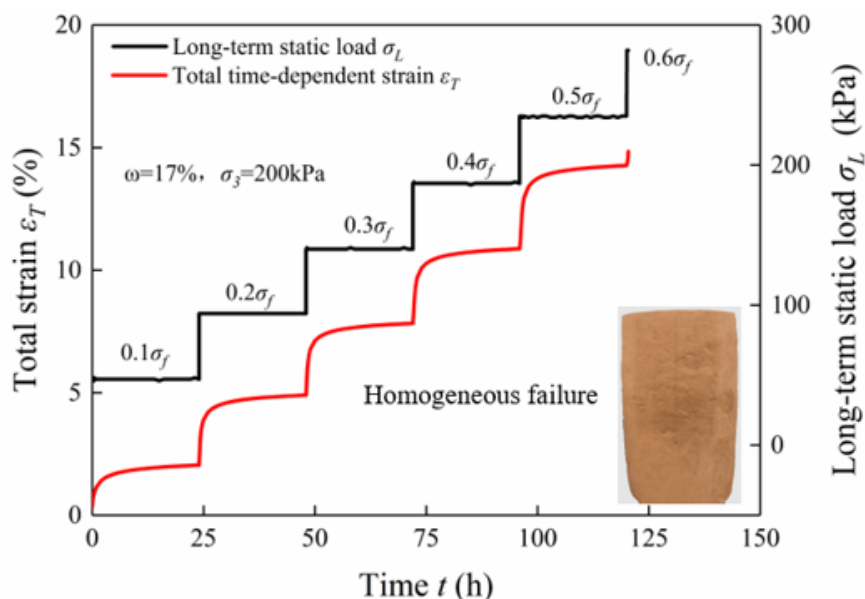

(b)

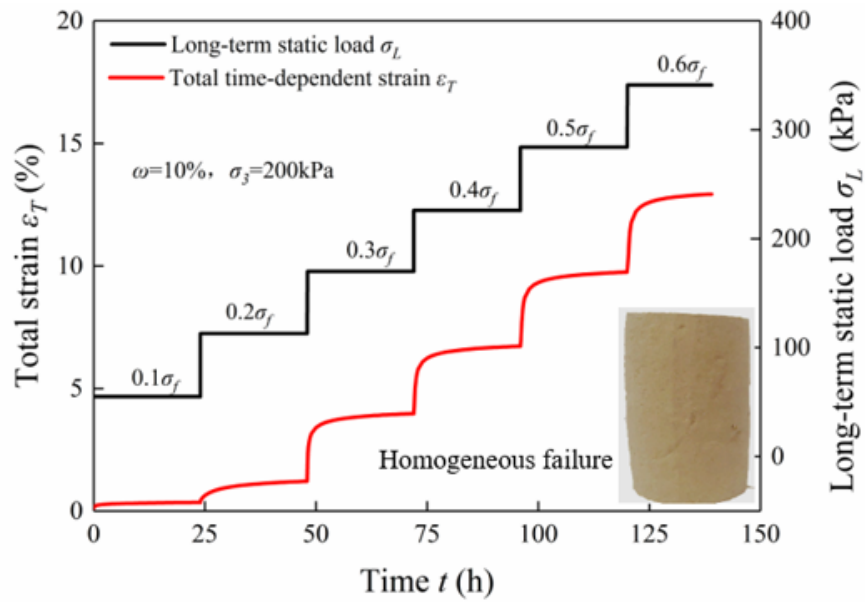

(d)

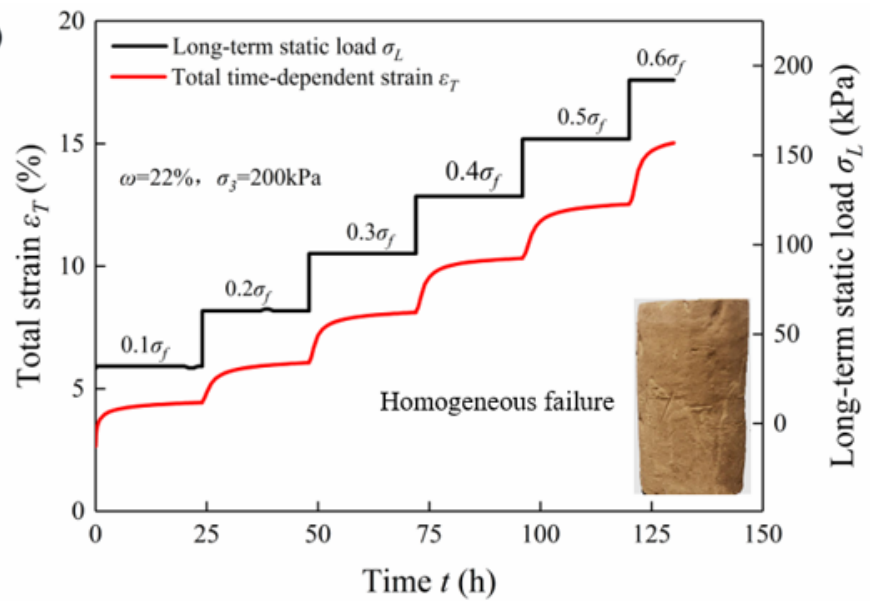

Figure 3

Curves of total time-dependent strain and long static load versus time of undisturbed loess under different moisture contents: (a) $\omega=5 \%$; (b) $\omega=10 \%$ (c) $\omega=17 \%$; (d) $\omega=22 \%$. $\omega$, moisture content; $\sigma 3$, confining pressure; of , shear strength. 

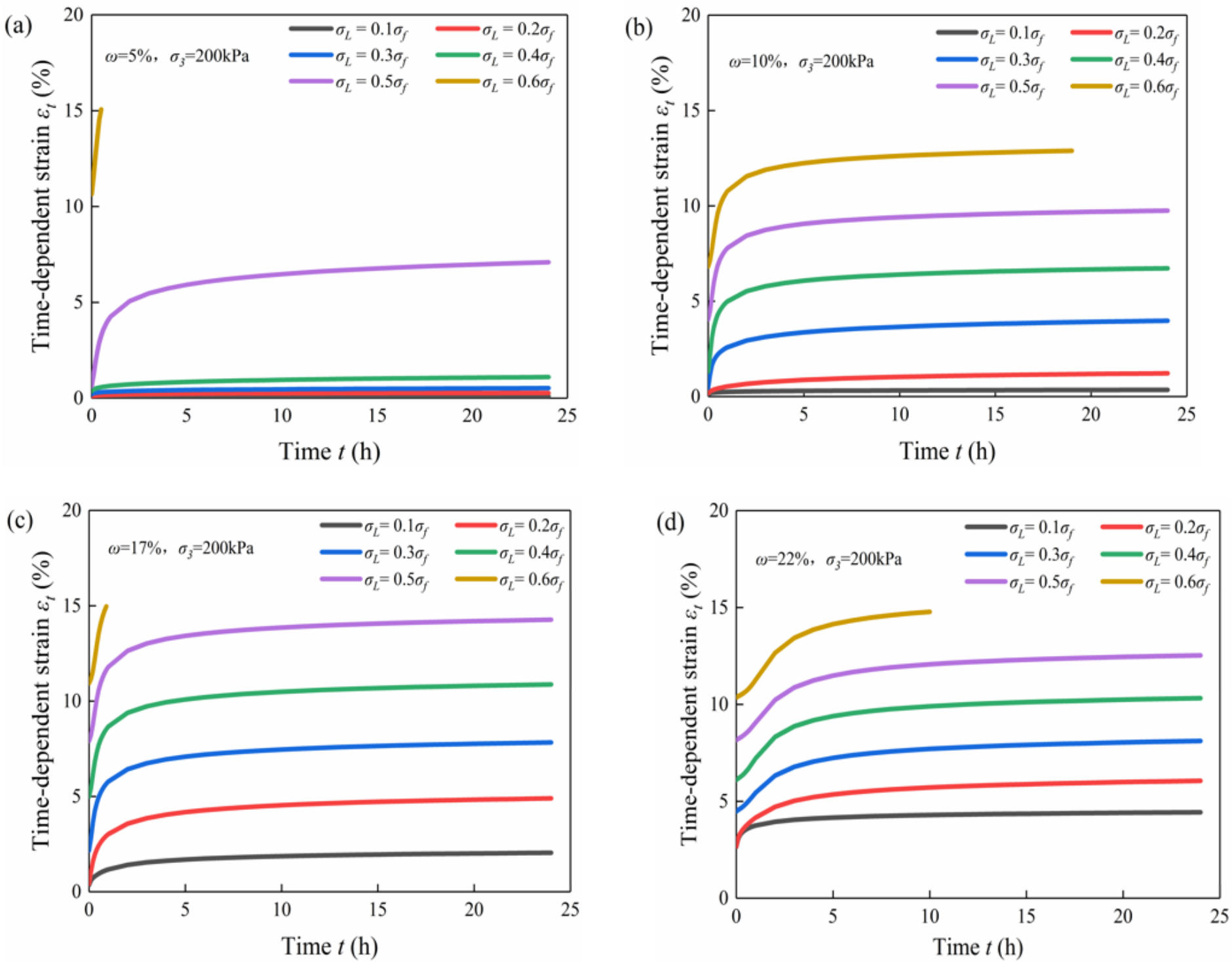

\section{Figure 4}

Curves of time-dependent strain versus time of undisturbed loess under different moisture contents: (a) $\omega=5 \%$; (b) $\omega=10 \%$ (c) $\omega=17 \%$; (d) $\omega=22 \%$. $\omega$, moisture content; $\sigma 3$, confining pressure; of , shear strength. 


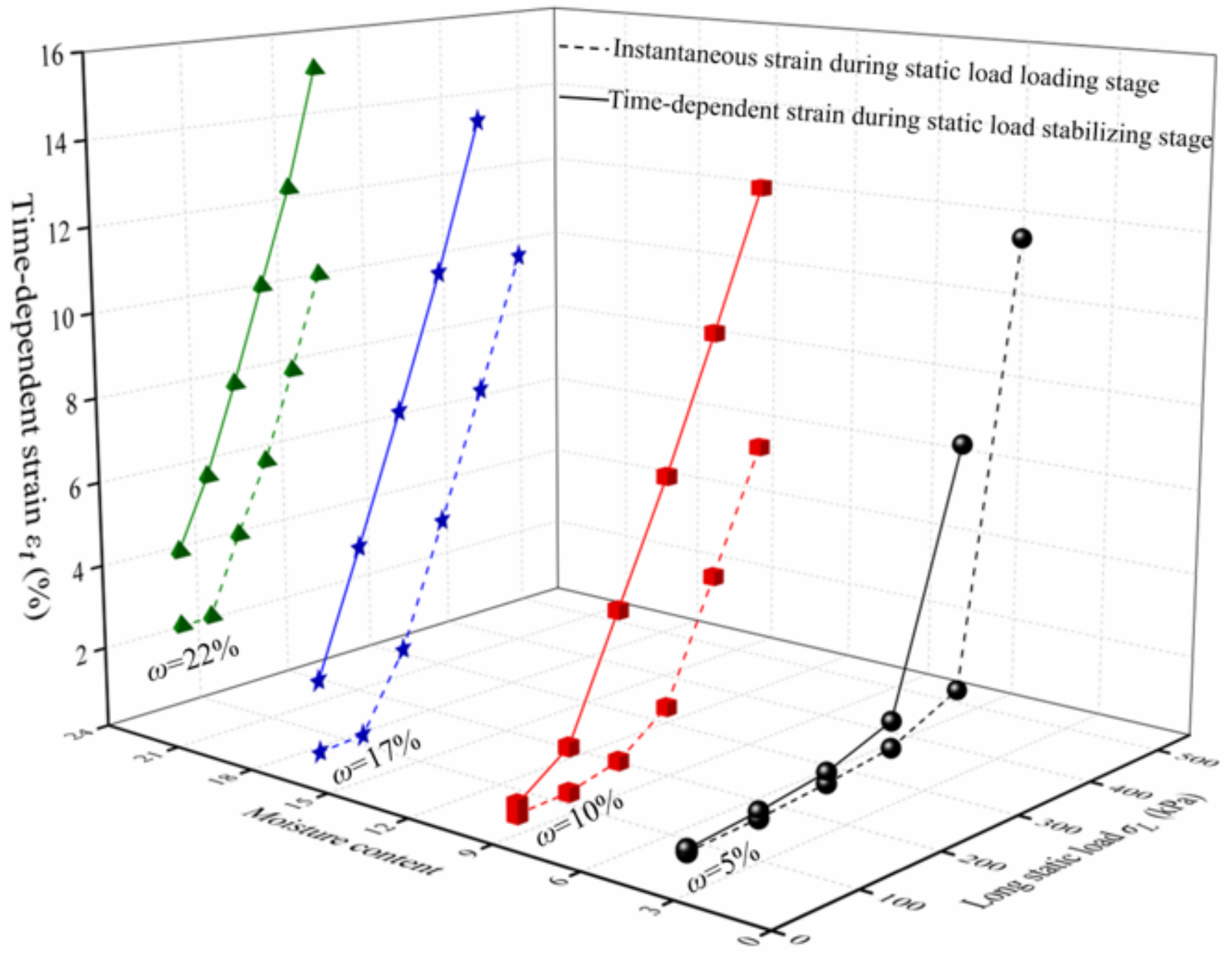

Figure 5

Different loading stages strain curves in the three-dimensional space of $\omega-\sigma L-\varepsilon t$. 

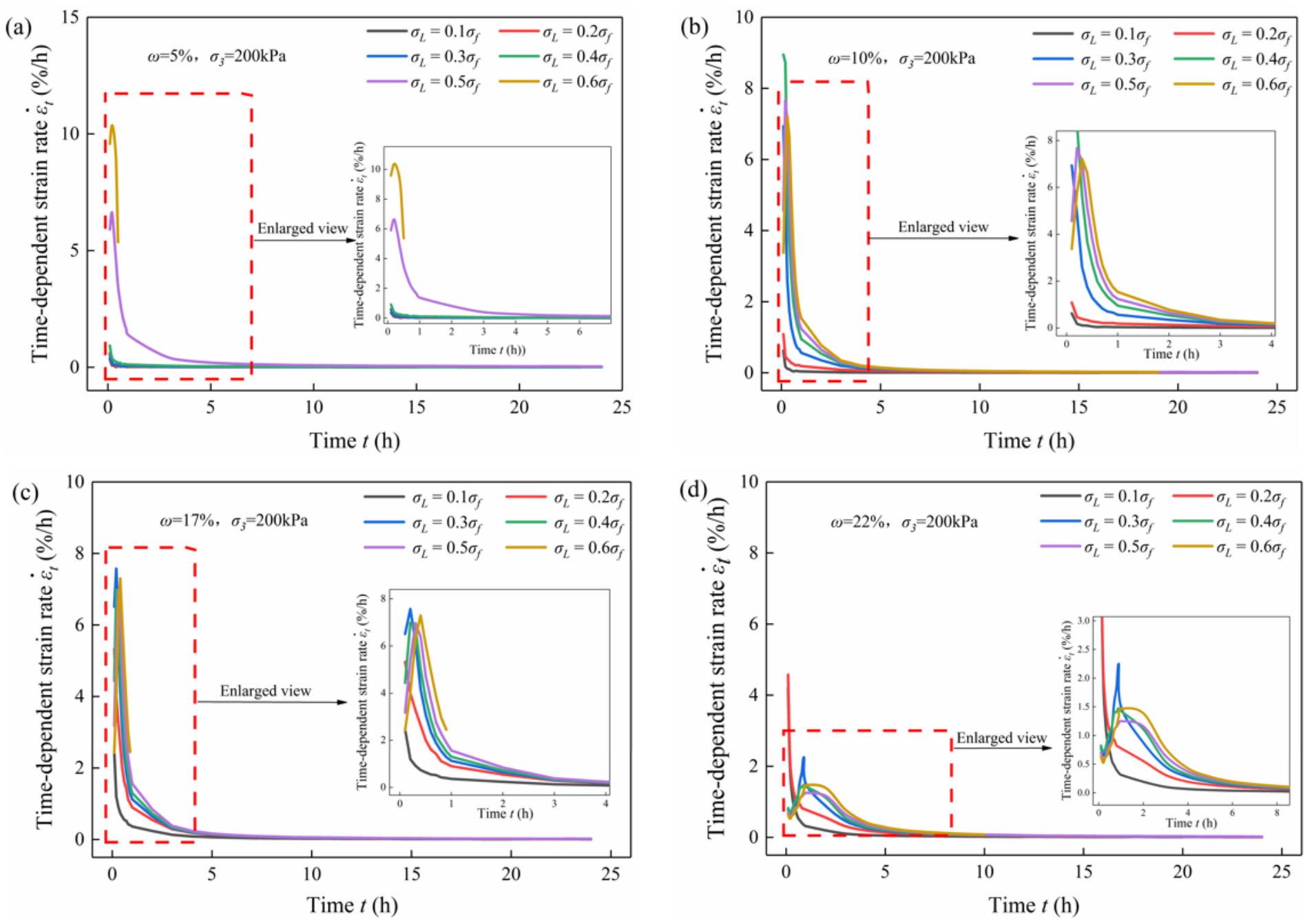

Figure 6

Curves of time-dependent strain rate versus time of undisturbed loess under different moisture contents: (a) $\omega=5 \%$; (b) $\omega=10 \%$ (c) $\omega=17 \%$; (d) $\omega=22 \%$. $\omega$, moisture content; $\sigma 3$, confining pressure; of , shear strength. 
(a)

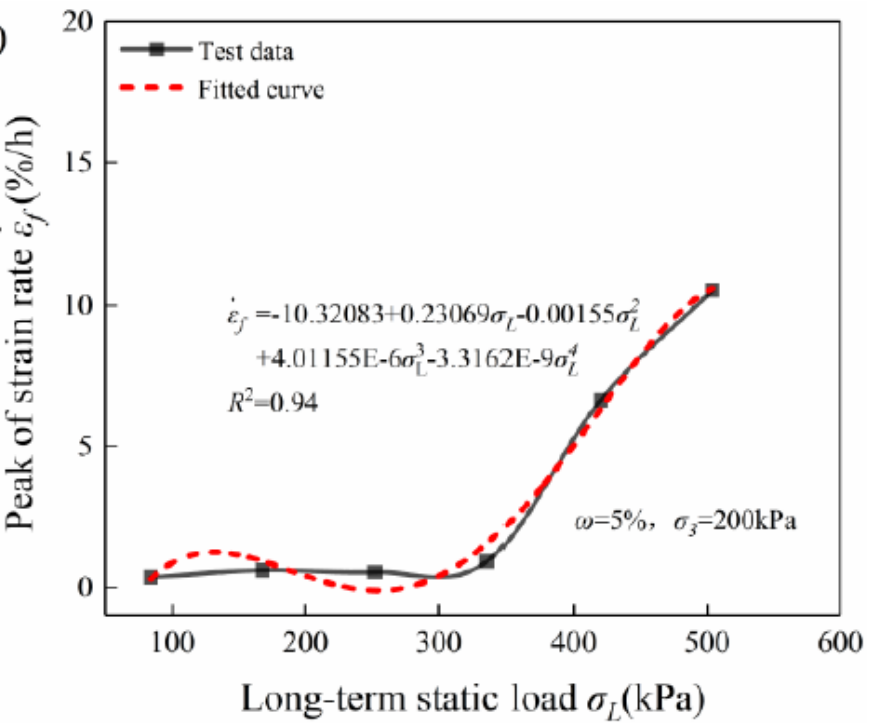

(c)

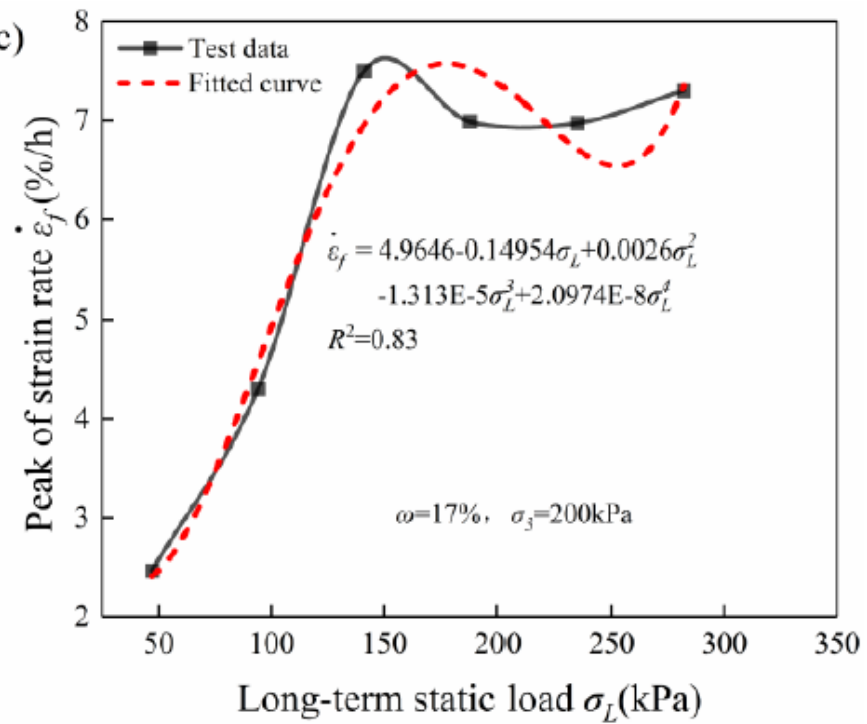

(b)
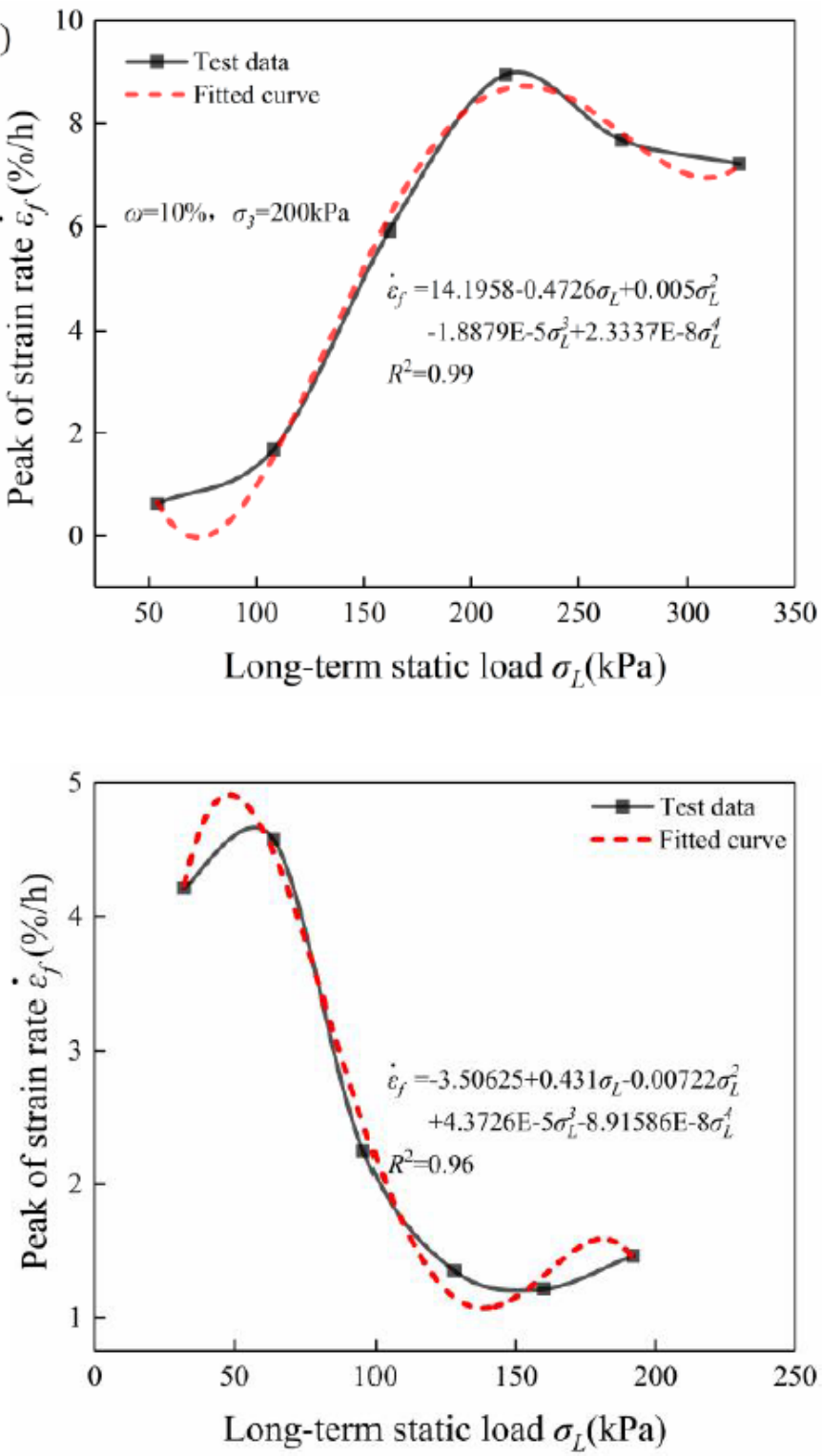

Figure 7

Curves of peak of strain rate versus long-term static load of undisturbed loess under different moisture contents: (a) $\omega=5 \%$; (b) $\omega=10 \%$ (c) $\omega=17 \%$; (d) $\omega=22 \%$. $\omega$, moisture content; $\sigma 3$, confining pressure. 
(a)
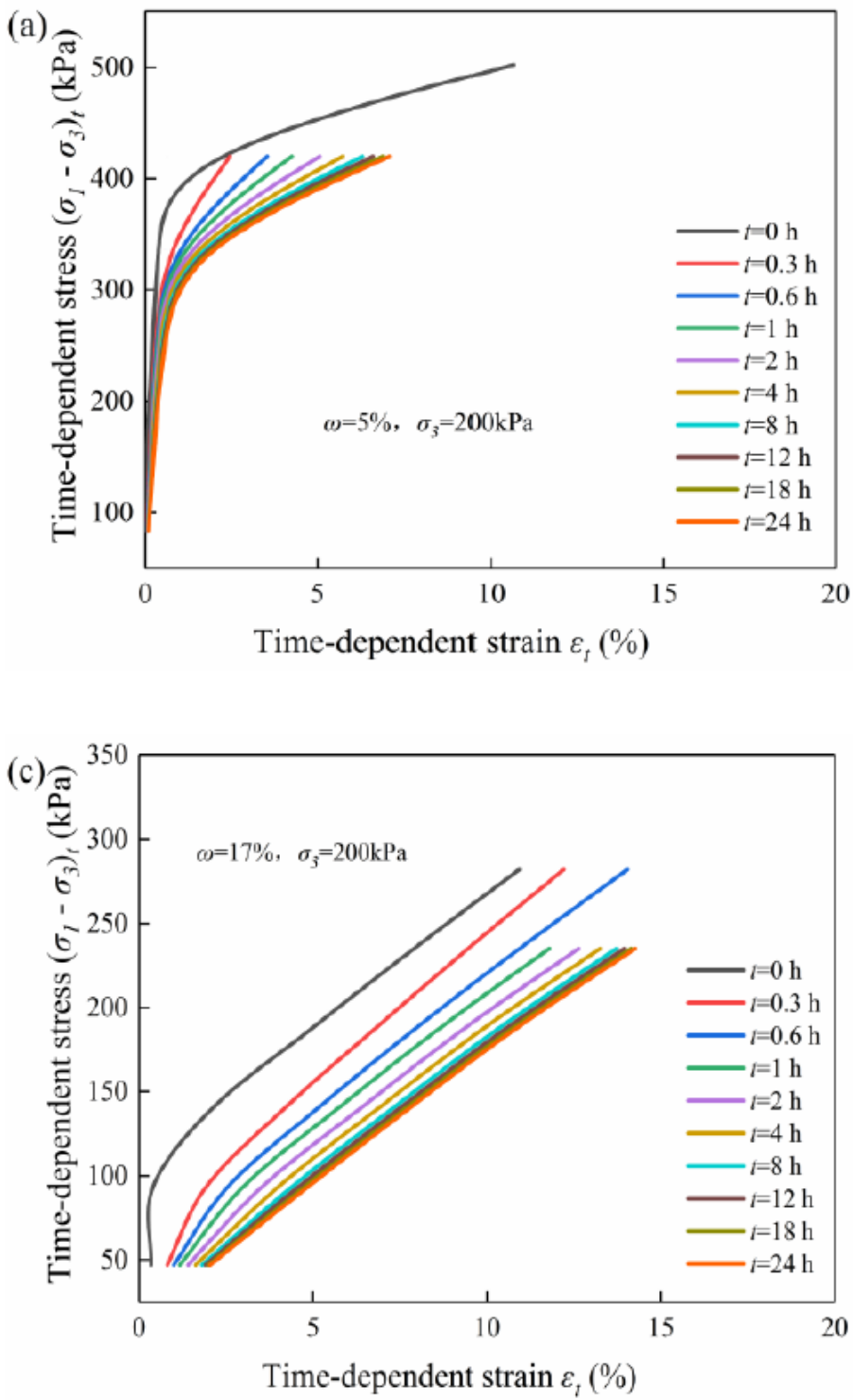
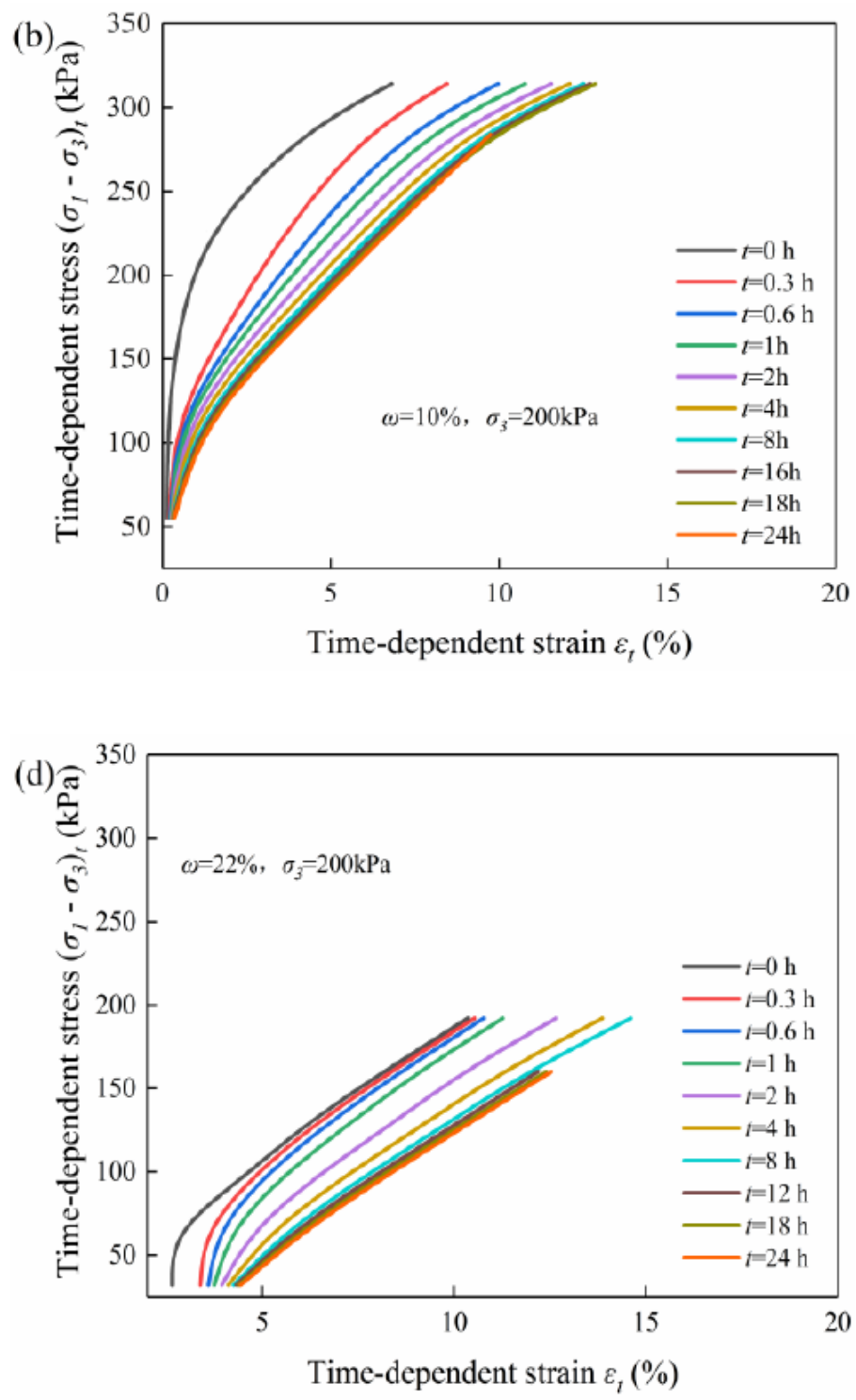

\section{Figure 8}

Curves of time-dependent stress versus time-dependent strain of undisturbed loess under different moisture contents: (a) $\omega=5 \%$; (b) $\omega=10 \%$ (c) $\omega=17 \%$; (d) $\omega=22 \%$. $\omega$, moisture content; $\sigma 3$, confining pressure; $t$, time.
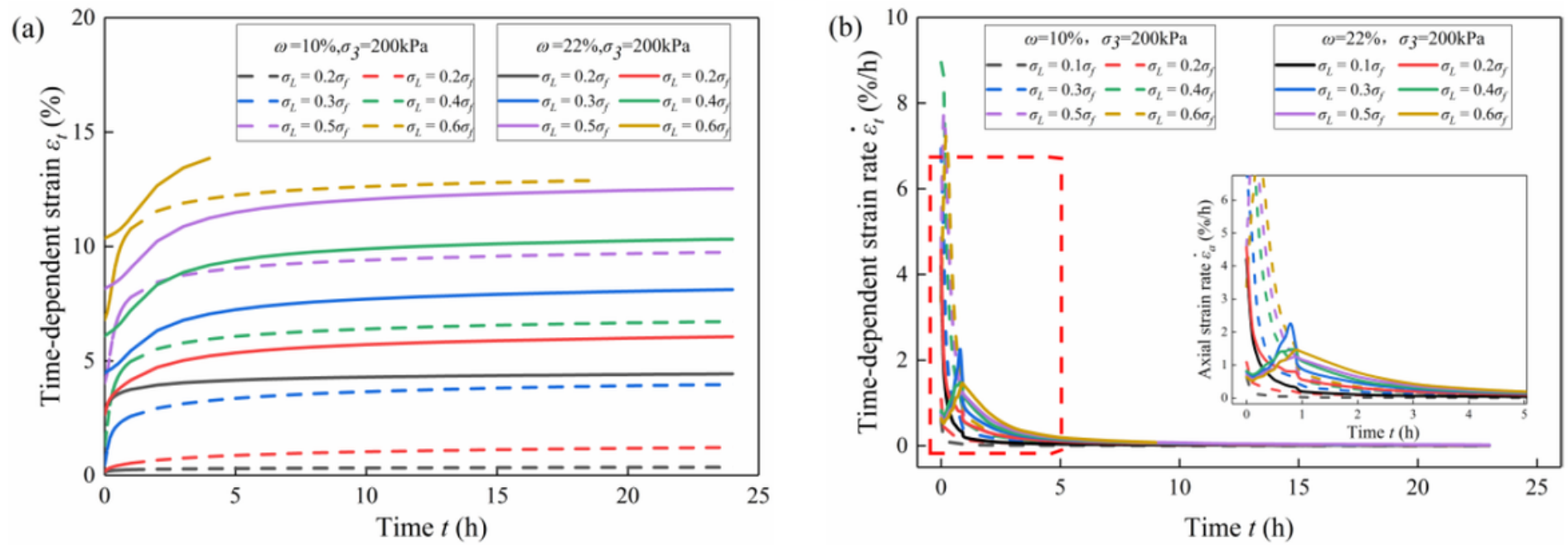


\section{Figure 9}

Comparison of time-dependent strain and strain rate versus time curves with $10 \%$ and $22 \%$ moisture contents: (a) time-dependent strain versus time (b) time-dependent strain rate versus time. $\omega$, moisture content; $\sigma 3$, confining pressure; of , shear strength.
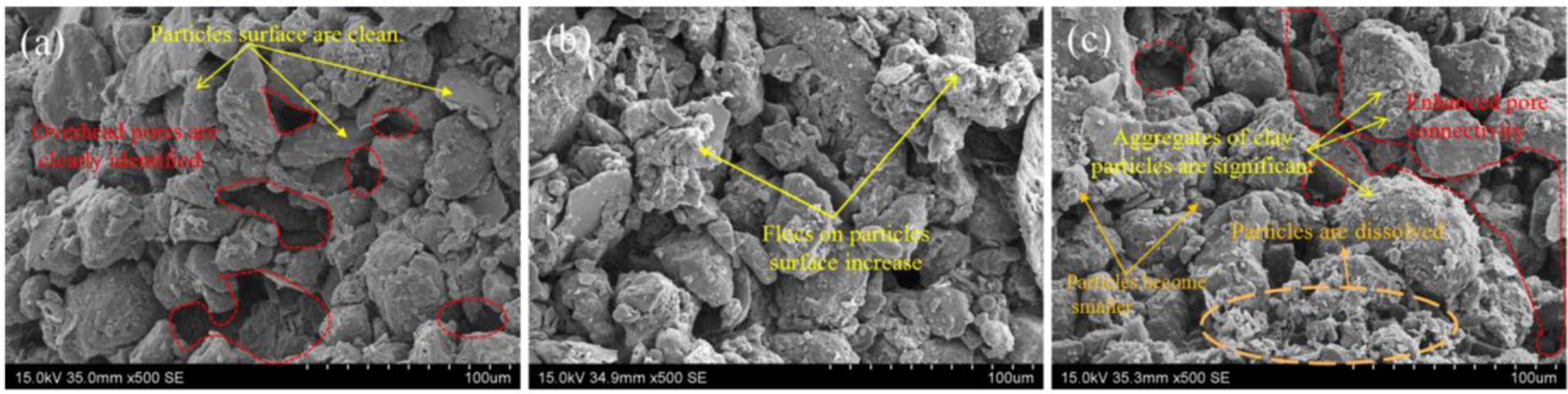

Figure 10

SEM images of the loess specimens under different contents before tests: (a) $\omega=10 \%$, (b) $\omega=17 \%$, (c) $\omega=22 \% . \omega$, moisture content. 


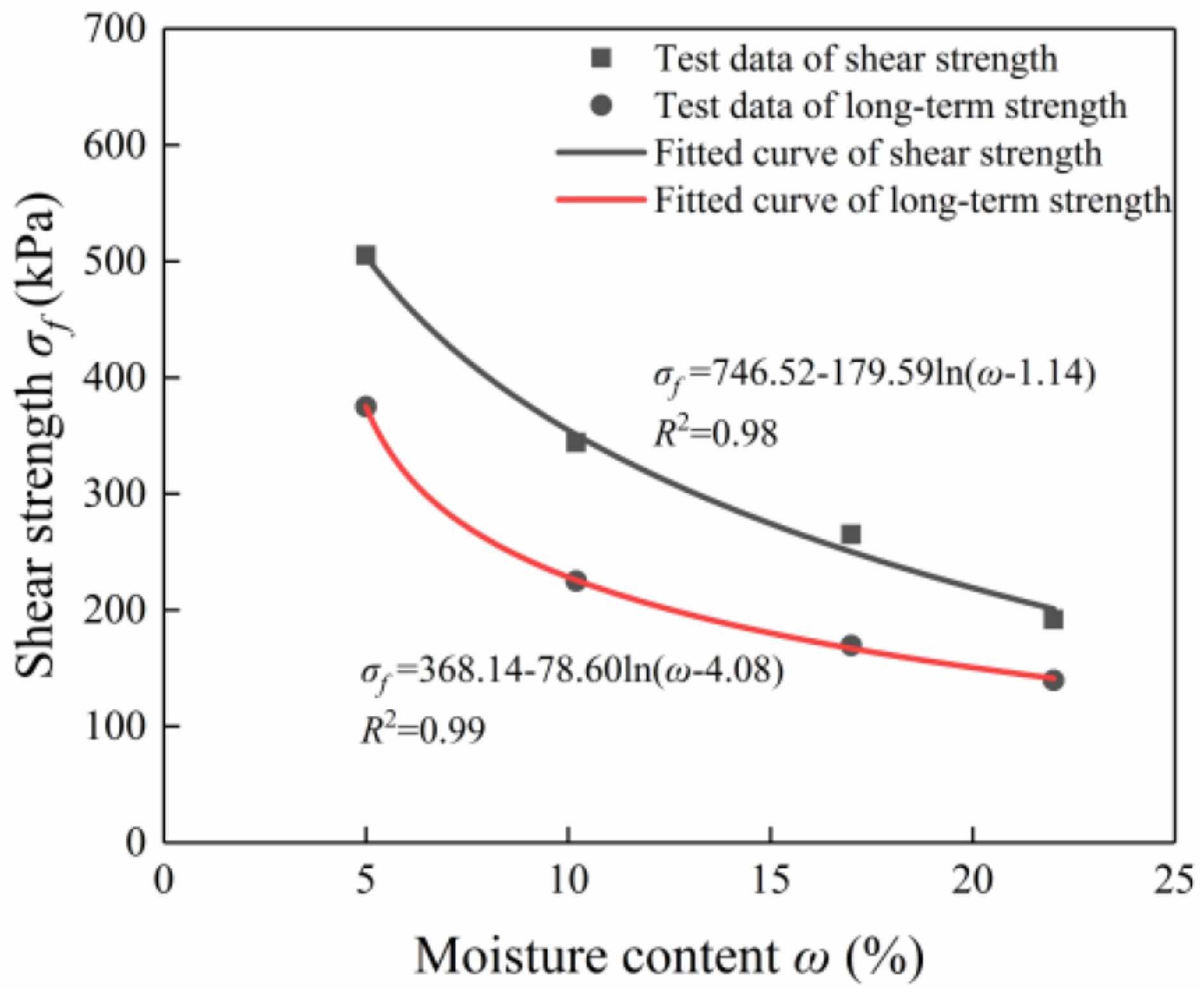

Figure 11

Relationship between moisture content versus shear strength and long-term strength of undisturbed loess.
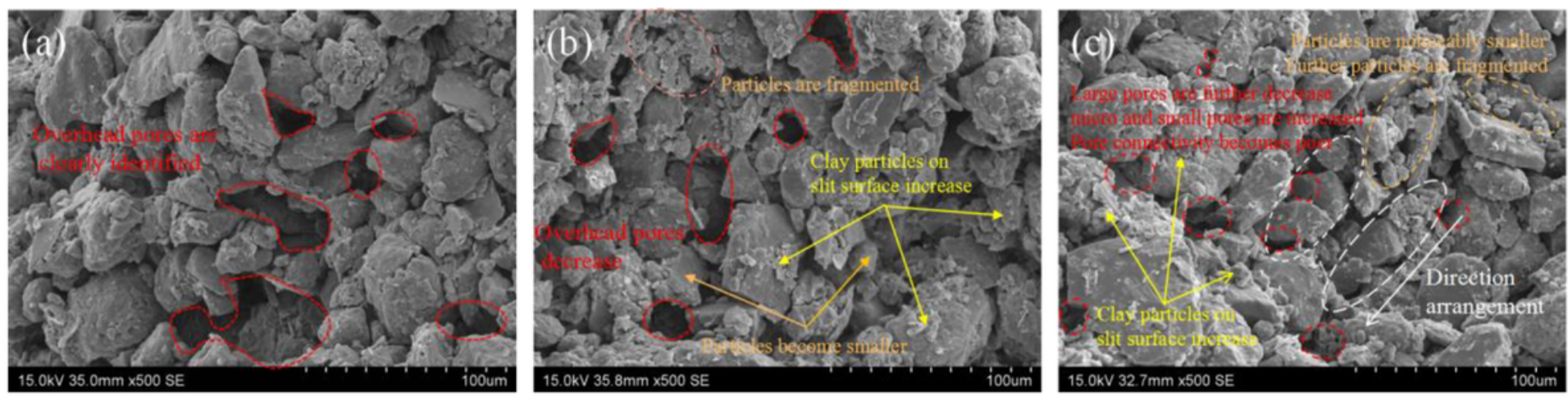

Figure 12 
SEM images of the $10 \%$ moisture content loess specimens before and after tests: (a) before test, (b) after triaxial shear test, (c) after triaxial creep test. 